\title{
Maternal obesity exacerbates insulitis and type 1 diabetes in non-obese diabetic mice
}

\author{
Hui Wang ${ }^{1,2}$, Yansong Xue ${ }^{1}$, Baolin Wang ${ }^{2}$, Junxing Zhao ${ }^{2}$, Xu Yan², Yan Huang ${ }^{2}$, \\ Min $\mathrm{Du}^{3}$ and Mei-Jun Zhu ${ }^{1,4}$ \\ ${ }^{1}$ School of Food Science, Washington State University, Pullman, Washington 99164, USA, ${ }^{2}$ Department of Animal \\ Science, University of Wyoming, Laramie, Wyoming 82071, USA, ${ }^{3}$ Department of Animal Sciences, Washington \\ State University, Pullman, Washington 99164, USA and ${ }^{4}$ School of Food Science, University of Idaho, Moscow, \\ Idaho 83844, USA
}

Correspondence should be addressed to M-J Zhu; Email: meijun.zhu@wsu.edu

\begin{abstract}
Accompanying the dramatic increase in maternal obesity, the incidence of type 1 diabetes (T1D) in children is also rapidly increasing. The objective of this study was to explore the effects of maternal obesity on the incidence of T1D in offspring using non-obese diabetic (NOD) mice, a common model for TID. Four-week-old female NOD mice were fed either a control diet (10\% energy from fat, CON) or a high-fat diet $(60 \%$ energy from fat) for 8 weeks before mating. Mice were maintained in their respective diets during pregnancy and lactation. All offspring mice were fed the CON to 16 weeks. Female offspring (16-week-old) born to obese dams showed more severe islet lymphocyte infiltration (major manifestation of insulitis) $(P<0.01)$, concomitant with elevated nuclear factor kappa-light-chain-enhancer of activated B cells p65 signaling $(P<0.01)$ and tumor necrosis factor alpha protein level $(P<0.05)$ in the pancreas. In addition, maternal obesity resulted in impaired $(P<0.05)$ glucose tolerance and lower $(P<0.05)$ serum insulin levels in offspring. In conclusion, maternal obesity resulted in exacerbated insulitis and inflammation in the pancreas of NOD offspring mice, providing a possible explanation for the increased incidence of T1D in children.

Reproduction (2014) 148 73-79
\end{abstract}

\section{Introduction}

Obesity is rapidly increasing worldwide, with the current obesity rate in USA more than $35 \%$. Accordingly, more than $30 \%$ of women aged $20-39$ years (child bearing age) are obese (Ogden et al. 2012). Meanwhile, according to the statistics from American Autoimmune Related Diseases Association and National Institutes of Health, up to 23.5 million Americans suffer from autoimmune disease and the prevalence is rising. Type 1 diabetes (T1D) is one of the major autoimmune diseases occurring in patients at young age, with about 30000 diagnosed with T1D annually (NIH autoimmune diseases statistics). The prevalence rate in developed countries is increasing at around 3\% per year (Gale 2002, Sgouroudis \& Piccirillo 2009).

Maternal obesity is considered as a risk factor for a number of adult diseases in offspring, especially cardiovascular disease and T2D, so-called 'developmental programming' (Barker et al. 2002, Nathanielsz et al. 2007, Li et al. 2011, Portha et al. 2011, Poston 2012, Reynolds \& Caton 2012). Recent epidemiological evidence indicates that maternal nutrition is correlated with the risk of childhood T1D (D'Angeli et al. 2010). $\mathrm{T} 1 \mathrm{D}$ is an autoimmune disease caused by gradual pancreatic lymphocyte infiltration and the destruction of insulin-producing $\beta$ cells in the islets.

The etiology of T1D is complicated and multifactorial, including both genetic and environmental risk factors. Epidemiological studies indicate that maternal intrauterine environment and early postnatal nutrition are among environmental factors contributing to the onset of T1D in children. Moreover, maternal over-nutrition or undernutrition predisposes offspring to metabolic disease syndromes by altering the development of less vital organs such as the pancreas (Hales \& Barker 2001, Harding 2001). Therefore, intrauterine environment, birth weight, and postnatal early life nutrition play a role in $\beta$-cell autoimmunity and are associated with a risk for T1D (Dahlquist et al. 1996, Kimpimaki et al. 2002, Oge et al. 2007). Indeed, the pancreatic $\beta$-cell function is altered in the fetuses of obese sheep (Zhang et al. 2011). Maternal low-protein diet, calorie restriction, or neonatal low-protein exposure are associated with delayed T1D onset or decreased apoptosis of $\beta$ cells (Boujendar et al. 2002, Oge et al. 2007, Chamson-Reig et al. 2009). Although there is recent epidemiological evidence supporting the association between maternal obesity and T1D in offspring (D'Angeli et al. 2010), the 
possible causal relationship between maternal obesity and increased risk of T1D in offspring has not been tested. Most available studies on maternal obesity and offspring metabolic diseases focus on T2D (Barker et al. 2002, Yan et al. 2010). Non-obese diabetic (NOD) mice are susceptible to the spontaneous development of T1D, with histological results showing peri-insulitis at 3-4 weeks of age and severe insulitis by 10 weeks of age (Andre et al. 1996). Using NOD mice as an experimental model, the aim of this study was to examine the effects of maternal obesity on the onset of T1D in offspring.

\section{Materials and methods}

\section{Animals and diet treatments}

Forty three-week-old female NOD/ShiLt] mice were obtained from the Jackson Laboratory (Bar Harbor, ME, USA). Mice were housed in a temperature-controlled room with a $12 \mathrm{~h}$ light: $12 \mathrm{~h}$ darkness cycle and were given food and water ad libitum. At 4 weeks of age, mice were randomly separated into two groups ( $n=20$ per group) and fed a control diet (CON: $19.2 \%$ protein, $67.3 \%$ carbohydrate, and $4.3 \%$ fat with $10 \%$ energy from fat; D12450B, Research diet, New Brunswick, NJ, USA) or a high-fat diet (HFD: $26.2 \%$ protein, $26.3 \%$ carbohydrate, and $34.9 \%$ fat with $60 \%$ of energy from fat; D12492, Research diet) ad libitum respectively for 8 weeks to induce obesity. These two diets mimic western 'healthy' and 'obesogenic' diets respectively and have been widely used for diet-induced obesity studies (Zhang et al. 1994). After inducing obesity, these female mice were mated with CON-fed male mice of a similar age. At birth, mice with abnormally large $(>8)$ or small litter sizes $(<4)$ were excluded. The size of remaining litters ( $n=10$ per treatment) were balanced to six pups per litter by reducing large and increasing small litters. Maternal mice were maintained on their respective CON or HFD diet during gestation and lactation. After weaning, all offspring were fed with CON diet so that the only difference between treatments was the maternal effect. The body weight and feed intake of both maternal and offspring mice were measured weekly. Because female NOD mice are known to be more susceptible to the development of T1D than male mice (Wicker et al. 1995), female offspring mice were chosen for further analyses to avoid the possible confounding effects of sex. All animal procedures were approved by the Institutional Animal Use and Care Committee of University of Wyoming.

\section{Tissue collection}

On the day of necropsy, after overnight fasting, one female mouse with average body weight from each litter was selected. These mice were anesthetized intraperitoneally with tribromoethanol $(250 \mathrm{mg} / \mathrm{kg}$ body weight). Blood samples were collected under anesthesia and serum was used for insulin analysis. Mice were killed by cervical dislocation, the pancreas was removed, and a small portion of the pancreas from each mouse was fixed in $4 \%(\mathrm{w} / \mathrm{v})$ paraformaldehyde dissolved in phosphate buffer (0.12 M; pH 7.4), processed, and embedded into paraffin per standard methods. The remaining pancreatic tissue was frozen in liquid nitrogen and stored at $-80^{\circ} \mathrm{C}$ for further biochemical analyses. In addition, the gonadal fat was collected and weighed because gonadal fat weight is highly correlated with adiposity in mice (Rogers \& Webb 1980).
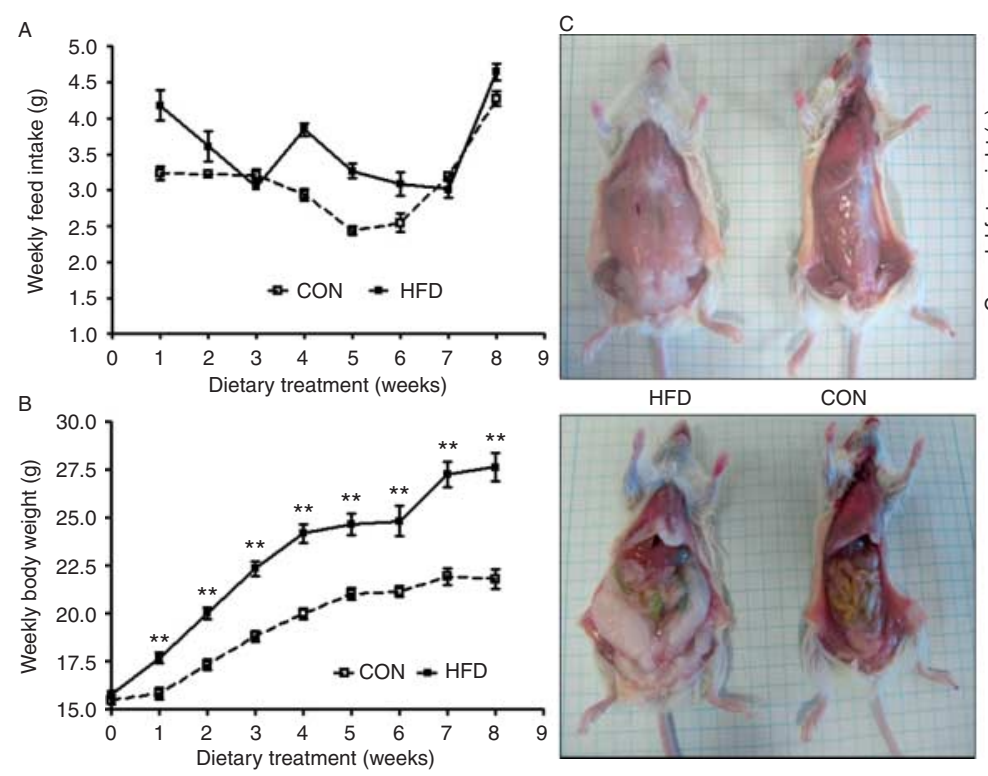
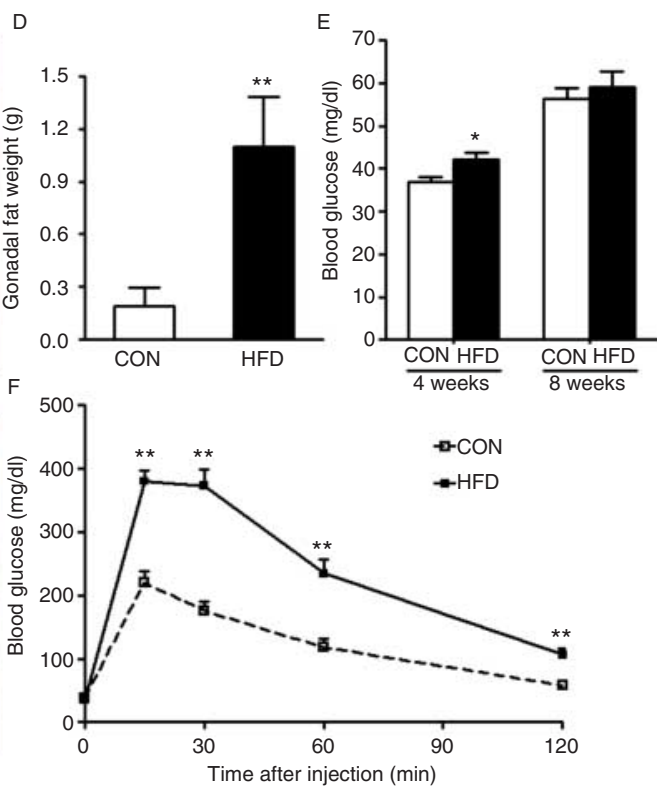

Figure 1 High-fat diet (HFD) induced obese phenotypes in maternal NOD mice. (A) Weekly feed intake; (B) weekly body weight; (C) representative images of fat tissue in maternal NOD mice of CON and HFD treatments at necropsy; (D) gonadal fat weight at necropsy; (E) base line blood glucose concentration of maternal NOD mice following 4 or 8 weeks of CON or HFD diet; and (F) intraperitoneal glucose tolerance test of maternal NOD mice following 8 weeks of CON or HFD treatment. Glucose was injected i.p. at $2 \mathrm{~g} / \mathrm{kg}$ body weight. Blood glucose concentrations were measured at $0,15,30,60$, and 120 min post-glucose injection (mean \pm S.E.M.; $* * P<0.01$ and ${ }^{*} P<0.05 ; n=20$ ). 


\section{Insulitis scoring}

The paraffin-embedded pancreatic tissues were sectioned at $5 \mu \mathrm{m}$ thickness. Sections were collected at $50 \mu \mathrm{m}$ interval, subjected to hematoxylin-eosin staining for evaluation of insulitis (lymphocyte infiltration) using the following scale: 0 , no infiltration; 1 , minimal focal infiltration; 2, peri-islet infiltration $(<25 \%)$; 3, intra-islet infiltration (25-50\%); and 4 , extensive infiltration ( $>50 \%$ ). The mean insulitis score of each offspring was calculated by dividing the sum of the insulitis scores by the number of islets examined. At least 20 islets per animal were analyzed by two independent examiners in a blind manner.

\section{Intraperitoneal glucose tolerance test}

Following 8-week treatment maternal NOD mice with CON or HFD diet ( $n=20$ per dietary group) or female offspring mice at age of 16 weeks (one mouse per litter of average body weight) were subjected to intraperitoneal glucose tolerance tests after overnight fasting with free access to water. Glucose was injected i.p. into mice at $2 \mathrm{~g} / \mathrm{kg}$ body weight. Glucose concentrations of each mouse were measured with a glucometer (Bayer's Contour, Tarrytown, NY, USA) at 0, 15, $30,60,90$, and $120 \mathrm{~min}$ after injection using blood collected from the tail vein. The glucose level of mice within dietary treatment at each time point post-injection was averaged and graphed against time post-injection. The total area under the glucose disposal curve (AUC) was calculated for each animal with GraphPad Prism 5.0 (San Diego, CA, USA) Software without subtracting the baseline, and means computed. Glucose levels at each time point were analyzed by repeated measures ANOVA and AUC was analyzed by ANOVA.

\section{Insulin analysis}

After overnight fasting, blood serum samples collected at necropsy day were used for insulin analysis. Serum insulin concentration was determined in duplicate in a single assay by commercial ELISA Kit (Linco Research, Inc., St Charles, MO, USA) according to the manufacturer's instructions. Mean intra-assay and inter-assay coefficient of variation for insulin was $<10 \%$.

\section{Immunoblotting analyses}

Immunoblotting analysis was conducted as described previously (Zhu et al. 2010, Yan et al. 2011). Antibodies against phospho-nuclear factor kappa-light-chain-enhancer of acti-

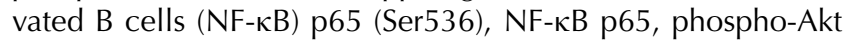
(Ser473), and Akt were purchased from Cell Signaling Technology (Beverly, MA, USA). Tumor necrosis factor alpha (TNF $\alpha$ ) antibody was purchased from Invitrogen Grand Island, NY, USA, while $\beta$-actin antibody was purchased from Sigma (St. Louis, MO, USA). Density of bands was normalized with reference to the $\beta$-actin content.

\section{Statistical analysis}

Data were analyzed as a complete randomized design using general linear model (GLM of Statistical Analysis System, SAS,
2000, Cary, NC, USA). For GTT, glucose levels at different time points were analyzed as repeated measures ANOVA using SAS Proc Mixed. Each maternal mouse and the subsequent litter were considered as an experimental unit. Means \pm S.E.M. are reported. The differences between group means were analyzed by ANOVA. Statistical significance is considered as $P<0.05$.
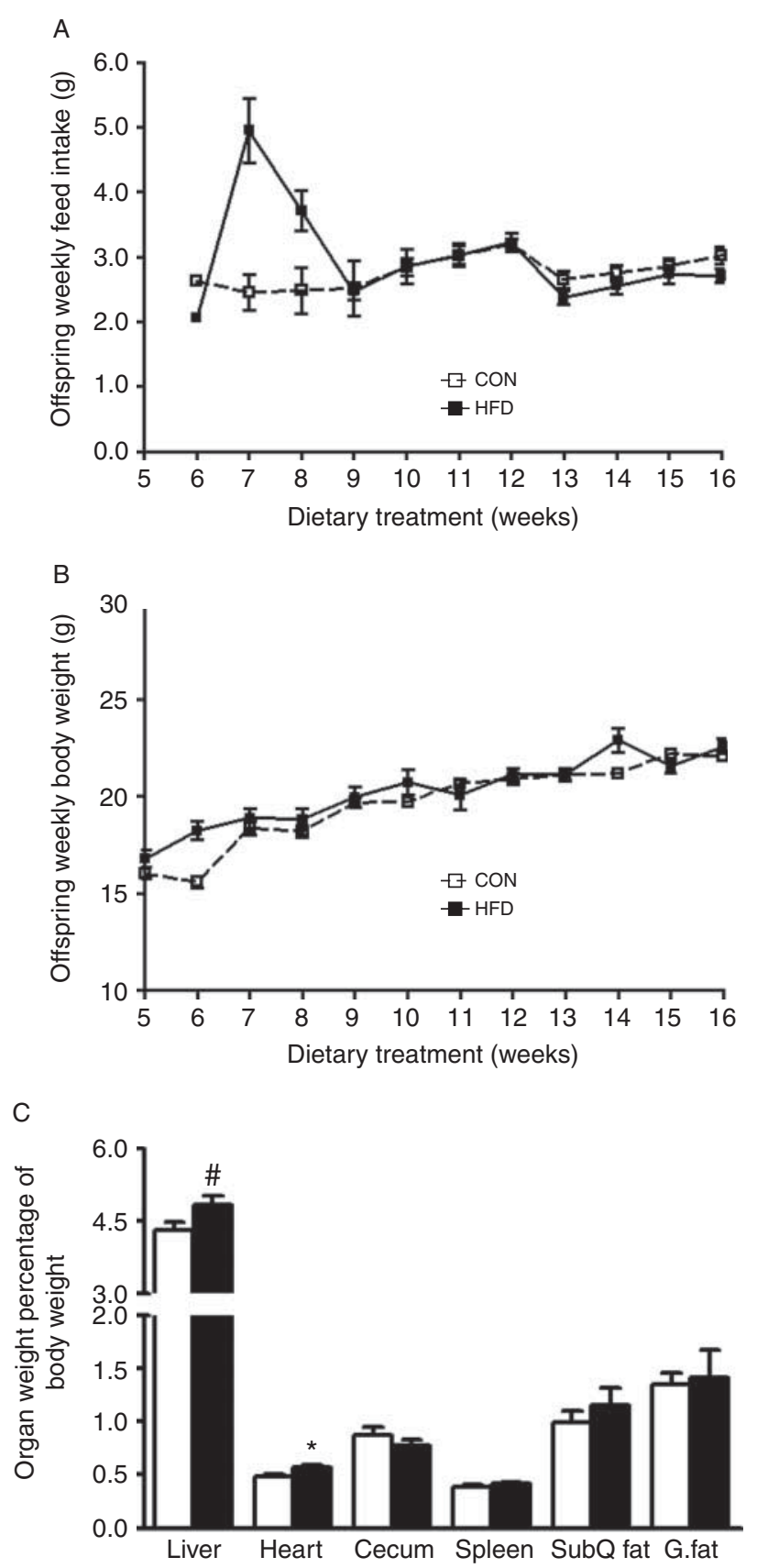

Figure 2 Effects of maternal obesity on female offspring (16-week-old) feed intake, and body, organ and tissue weights. (A) Offspring weekly feed intake; (B) offspring weekly body weight; and (C) organ weights normalized as a percentage of total body weight (mean \pm S.E.M.; ${ }^{*} P<0.05$ and $\left.{ }^{*} P<0.10 ; n=10\right)$. 


\section{Results}

\section{HFD leading to obese phenotype in NOD mice}

During 8 weeks of dietary treatment, the overall feed intake was similar between CON and HFD-fed maternal NOD mice (Fig. 1A). Starting the first week of feeding, maternal NOD mice fed with HFD gained more body weight than those fed the CON diet (Fig. 1B, $P<0.01$ ). After 8 weeks of dietary treatment, HFD-fed mice developed obesity with more gonadal fat (Fig. 1C and $D)$. The fasting baseline blood glucose level was higher (Fig. 1E, $P<0.05$ ) in NOD mice fed with HFD than those in CON fed mice at 4 weeks of dietary treatments. Although the fasting baseline blood glucose was similar, the HFD-fed mice had impaired glucose tolerance compared to those fed CON diet after 8 weeks of dietary treatments (Fig. $1 \mathrm{~F}, P<0.01$ ).

\section{Body weight of female NOD offspring}

Offspring born to CON and HFD-fed dam had similar food intake and body weight (Fig. 2A and B). The ratios of heart weight:offspring body weight were higher $(P<0.05)$ in female offspring exposed to maternal obesity (Fig. 2C).

\section{Offspring from HFD dams developed more severe insulitis}

Figure $3 \mathrm{~A}$ illustrates the histological scoring system that was used to evaluate effects of maternal obesity on pancreatic insulitis of female offspring. As shown in Fig. 3B and C, the female offspring exposed to maternal
HFD showed more severe $(P<0.01)$ insulitis than those from CON dams.

\section{Pancreatic inflammatory signaling pathways in female offspring}

Consistent with more severe lymphocyte infiltration, the major mediator of inflammatory NF- $\mathrm{BB}$ signaling, phospho-p65, was elevated $(P<0.01)$ in pancreatic tissue of offspring from HFD-fed dams (Fig. 4A), suggesting an exaggerated pancreatic inflammatory response. Accordingly, higher TNF $\alpha$ protein level was also detected in pancreatic tissue of offspring born to HFD-fed dams (Fig. 4B, $P<0.05$ ).

\section{Insulin signaling in female offspring}

Although the intraperitoneal glucose tolerance test at 16 weeks of age revealed relatively minor differences, the AUC was greater (Fig. 5A, $P<0.05$ ) in offspring from HFD-fed dams, suggesting impaired glucose tolerance. This could be related to the trend of reduction of phospho-Akt in pancreas tissue of offspring from HFDfed dam (Fig. 5B, $P<0.10$ ). Conversely, offspring born from HFD-fed dams had lower $(P<0.05)$ serum insulin level compared with those from CON fed dam (Fig. 5C), indicating decreased insulin production that could also explain the impaired glucose tolerance.

\section{Discussion}

While limited studies have shown that maternal obesity impairs fetal pancreatic $\beta$-cell development and
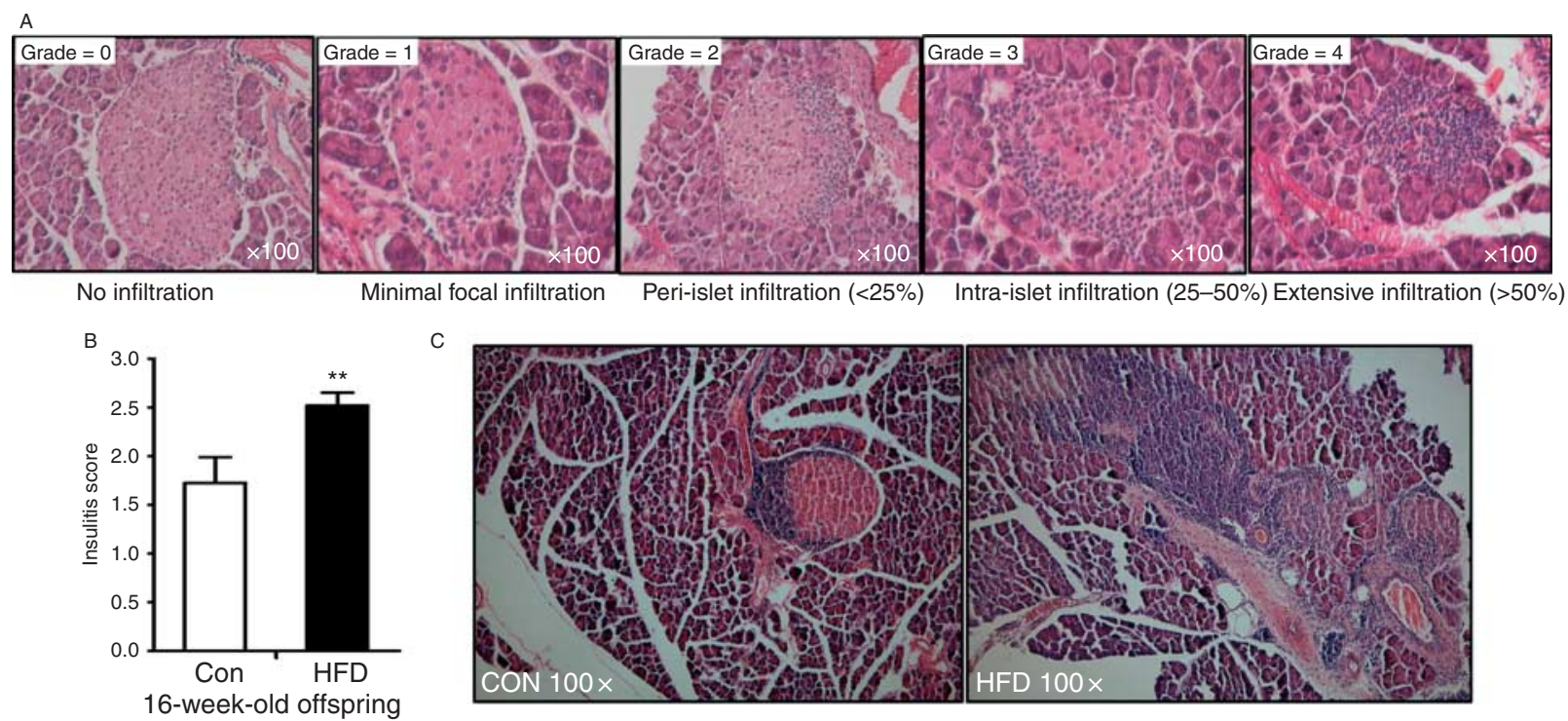

Figure 3 Pancreatic pathobiological changes of female offspring mice (16-week-old) exposed to maternal CON or HFD diet. The paraffin-embedded pancreatic tissues were sectioned at $5 \mu \mathrm{m}$ thickness and subjected to hematoxylin-eosin staining. (A) Insulitis (lymphocyte infiltration in the islet of pancreas) scoring system; (B) pancreatic insulitis score; and (C) representative images of pancreatic islets of CON and HFD offspring (mean \pm s.E.M.; $* * P<0.01 ; n=10)$. 
A

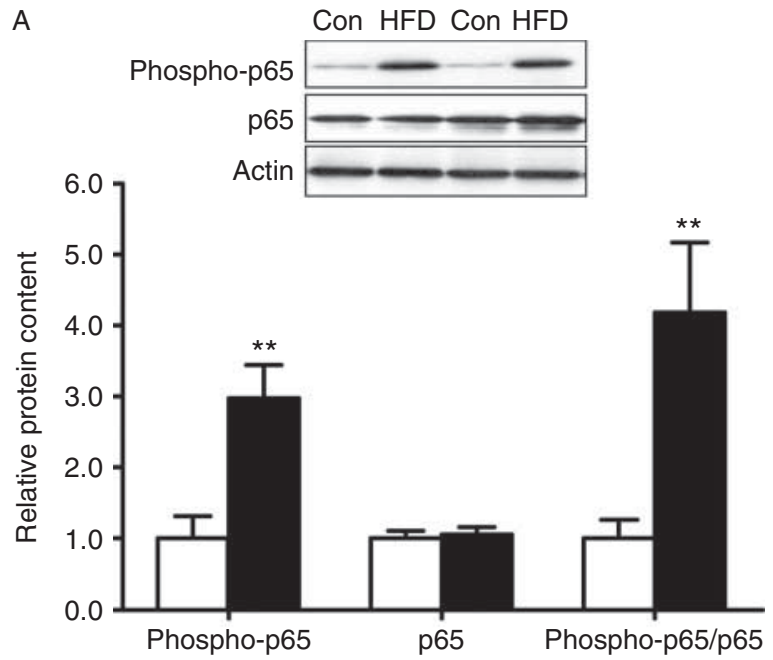

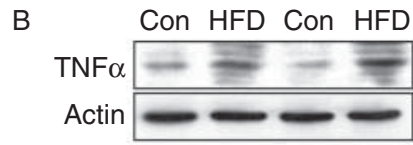

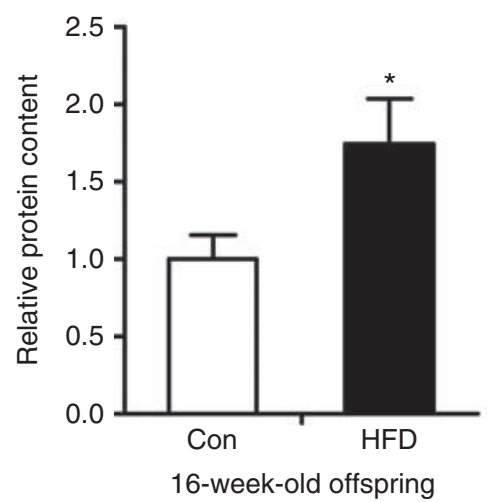

Figure 4 Inflammatory signaling (A) and inflammatory cytokine content (B) in pancreas tissues of female offspring (16-week-old) exposed to maternal CON (open square) or HFD (closed square) diet. Pancreatic tissues were subjected to immunoblotting. (A) Elevation of NF- $\kappa B$ signaling shown by increased ratio of phospho-p65:p65 level in HFD compared to CON offspring pancreas and (B) enhanced TNF $\alpha$ protein level in HFD compared to CON offspring pancreas (mean \pm s.E.M.; ${ }^{* *} P<0.01$ and $\left.* P<0.05 ; n=10\right)$.

postnatal function (Han et al. 2005, Ford et al. 2009, Zhang et al. 2011), the relationship between maternal obesity and the onset of T1D in offspring remains unclear. To clarify this relationship, we induced obesity in NOD mice to test whether maternal obesity predisposes offspring to T1D. NOD mice are prone to develop TID and are the most frequently used model for studying this disease. WT mice were not used here because their incidence of TID is too low. In addition to obesity, NOD maternal mice had an elevated fasting blood glucose level after 4 weeks of HFD treatment and impaired glucose tolerance after 8 weeks. Together, these maternal mice were obese, with elevated blood glucose and impaired glucose tolerance, similar to obese human mothers.

Maternal obesity accelerates the development of T1D in offspring mice. We observed severe lymphocyte infiltration in the pancreatic islets of offspring exposed to maternal obesity, showing the increased degree of insulitis. Consistent with lymphocyte infiltration data, pancreatic tissue in offspring from HFD-fed dam had augmented TNF $\alpha$ content and heightened inflammatory NF- $\kappa B$ signaling as indicated by elevated p65 activation. These data are in line with previous reports, where maternal obesity elevates cytokines and inflammatory signaling in other tissues of fetuses and offspring (White et al. 2008, Bilbo \& Tsang 2010, Leibowitz et al. 2012). The observed inflammatory responses in offspring pancreatic tissue from obese dams might be a contributing factor to their exaggerated insulitis (Kurylowicz \& Nauman 2008, Thomas et al. 2013). Cytokines (IL1 $\beta$, $\mathrm{TNF} \alpha$, and IFN $\gamma$ ) can induce $\beta$-cell stress leading to apoptosis in human and rodent T1D models by increasing the expression of pro-apoptotic proteins (Rabinovitch 1998, Rabinovitch \& Suarez-Pinzon 1998, Pavlovic et al. 2000, Petrovsky et al. 2002). Our data are in line with a previous report, where maternal obesity resulted in pancreatic dysfunction in offspring and was
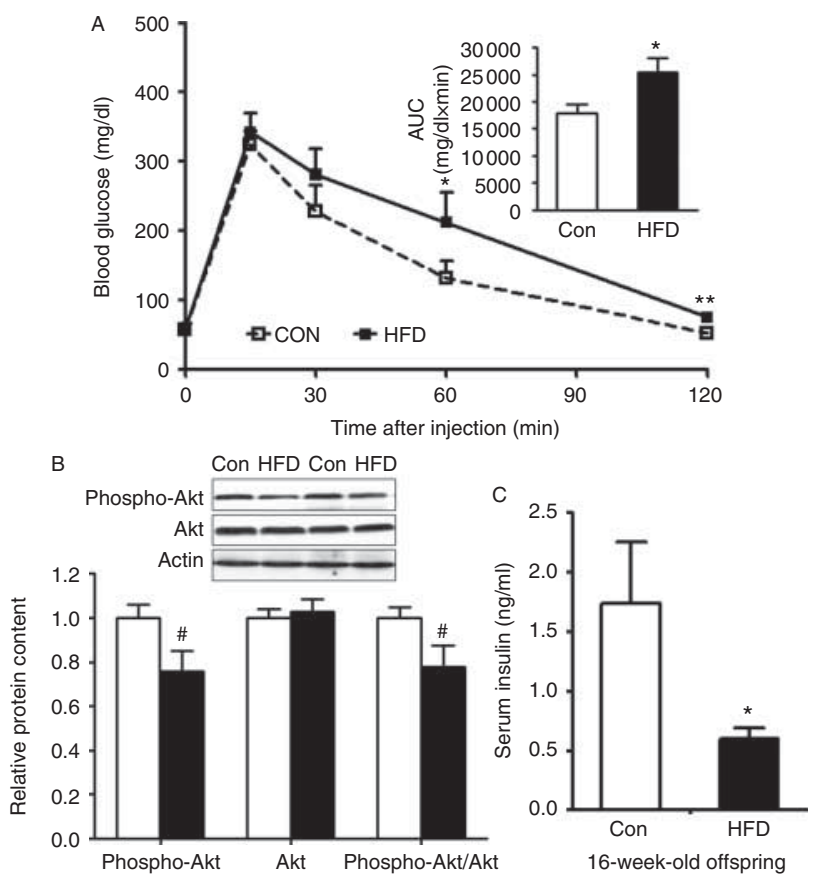

Figure 5 Intraperitoneal glucose tolerance and insulin signaling of the pancreas of female offspring (16-week-old) exposed to maternal CON (open square) or HFD (closed square) diet. (A) Intraperitoneal glucose tolerance test with area under the curve (AUC). Glucose was injected i.p. at $2 \mathrm{~g} / \mathrm{kg}$ body weight. Blood glucose concentrations were measured at $0,15,30,60$, and 120 min after glucose injection; (B) pancreatic phospho-Akt and total Akt levels measured by immunoblotting; and $(C)$ fasting blood serum insulin level (mean \pm S.E.M.; ${ }^{* *} P<0.01 ;{ }^{*} P<0.05$; and ${ }^{\#} P<0.10 ; n=10$ ). 
associated with the development of T2D. However, in that study, the possible link of maternal obesity to T1D was not studied or discussed (Han et al. 2005). Consistent with our observations, maternal calorie restriction and low maternal nutrition has been shown to delay onset of T1D (Oge et al. 2007, Chamson-Reig et al. 2009).

We also detected glucose intolerance in maternal obesity offspring, which coincided with lower insulin levels. Akt activation contributes to insulin sensitivity in peripheral organs and also could suppress stress-induced $\beta$-cell death (Leibiger et al. 2008). We observed a tendency of decreased Akt phosphorylation in pancreas of maternal obesity offspring. This downregulated Akt signaling in pancreas might further accelerate pancreatic cell apoptosis.

In summary, maternal obesity resulted in exaggerated insulitis, impaired glucose tolerance, and reduced baseline insulin in female NOD offspring by 16 weeks of age. The mechanism for accelerated onset of T1D due to maternal obesity might be associated with augmented inflammation in the offspring pancreas. Up to now, the effect of maternal obesity on offspring metabolic diseases has been focused on T2D. To our knowledge, this is the first report showing that maternal obesity predisposes offspring to T1D, which is an important feature to our understanding regarding the long-term programming effects of maternal obesity on offspring health. Considering that more than $30 \%$ pregnant women are obese, the current finding has important clinical implications.

\section{Declaration of interest}

The authors declare that there is no conflict of interest that could be perceived as prejudicing the impartiality of the research reported.

\section{Funding}

Funding was supported by NIH R15HD073864 and $\mathrm{NIH}$ INBRE P20RR016474.

\section{Acknowledgements}

The authors gratefully acknowledged Dr Joseph R Powers in the School of Food School at Washington State University for his critical review on the manuscript and Mr David Hanna in the Department of Animal Science at University of Wyoming for taking care of mice and facilitate experiments.

\section{References}

Andre I, Gonzalez A, Wang B, Katz J, Benoist C \& Mathis D 1996 Checkpoints in the progression of autoimmune disease: lessons from diabetes models. PNAS 93 2260-2263. (doi:10.1073/pnas.93.6.2260)

Barker DJ, Eriksson JG, Forsen T \& Osmond C 2002 Fetal origins of adult disease: strength of effects and biological basis. International Journal of Epidemiology 31 1235-1239. (doi:10.1093/ije/31.6.1235)
Bilbo SD \& Tsang V 2010 Enduring consequences of maternal obesity for brain inflammation and behavior of offspring. FASEB Journal 24 2104-2115. (doi:10.1096/fj.09-144014)

Boujendar S, Reusens B, Merezak S, Ahn MT, Arany E, Hill D \& Remacle C 2002 Taurine supplementation to a low protein diet during foetal and early postnatal life restores a normal proliferation and apoptosis of rat pancreatic islets. Diabetologia 45 856-866. (doi:10.1007/s00125-0020833-6)

Chamson-Reig A, Arany EJ, Summers K \& Hill DJ 2009 A low protein diet in early life delays the onset of diabetes in the non-obese diabetic mouse. Journal of Endocrinology 201 231-239. (doi:10.1677/JOE-09-0002)

Dahlquist G, Bennich SS \& Kallen B 1996 Intrauterine growth pattern and risk of childhood onset insulin dependent (type I) diabetes: population based case-control study. BMJ 313 1174-1177. (doi:10.1136/bmj.313. 7066.1174)

D'Angeli MA, Merzon E, Valbuena LF, Tirschwell D, Paris CA \& Mueller BA 2010 Environmental factors associated with childhood-onset type 1 diabetes mellitus: an exploration of the hygiene and overload hypotheses. Archives of Pediatrics \& Adolescent Medicine 164 732-738.

Ford SP, Zhang L, Zhu M, Miller MM, Smith DT, Hess BW, Moss GE, Nathanielsz PW \& Nijland MJ 2009 Maternal obesity accelerates fetal pancreatic $\beta$-cell but not $\alpha$-cell development in sheep: prenatal consequences. American Journal of Physiology. Regulatory, Integrative and Comparative Physiology 297 R835-R843. (doi:10.1152/ajpregu. $00072.2009)$

Gale EA 2002 The rise of childhood type 1 diabetes in the 20th century. Diabetes 51 3353-3361. (doi:10.2337/diabetes.51.12.3353)

Hales CN \& Barker DJ 2001 The thrifty phenotype hypothesis. British Medical Bulletin 60 5-20. (doi:10.1093/bmb/60.1.5)

Han J, Xu J, Epstein PN \& Liu YQ 2005 Long-term effect of maternal obesity on pancreatic $\beta$ cells of offspring: reduced $\beta$ cell adaptation to high glucose and high-fat diet challenges in adult female mouse offspring. Diabetologia 48 1810-1818. (doi:10.1007/s00125-005-1854-8)

Harding JE 2001 The nutritional basis of the fetal origins of adult disease. International Journal of Epidemiology 30 15-23. (doi:10.1093/ije/30.1.15)

Kimpimaki T, Kulmala P, Savola K, Kupila A, Korhonen S, Simell T, Ilonen J, Simell O \& Knip M 2002 Natural history of $\beta$-cell autoimmunity in young children with increased genetic susceptibility to type 1 diabetes recruited from the general population. Journal of Clinical Endocrinology and Metabolism 87 4572-4579. (doi:10.1210/jc.2002-020018)

Kurylowicz A \& Nauman J 2008 The role of nuclear factor-kappaB in the development of autoimmune diseases: a link between genes and environment. Acta Biochimica Polonica 55 629-647.

Leibiger IB, Leibiger B \& Berggren PO 2008 Insulin signaling in the pancreatic $\beta$-cell. Annual Review of Nutrition 28 233-251. (doi:10.1146/ annurev.nutr.28.061807.155530)

Leibowitz KL, Moore RH, Ahima RS, Stunkard AJ, Stallings VA, Berkowitz RI, Chittams JL, Faith MS \& Stettler N 2012 Maternal obesity associated with inflammation in their children. World Journal of Pediatrics 8 76-79. (doi:10.1007/s12519-011-0292-6)

Li M, Sloboda DM \& Vickers MH 2011 Maternal obesity and developmental programming of metabolic disorders in offspring: evidence from animal models. Experimental Diabetes Research 2011 592408. (doi:10.1155/ 2011/592408)

Nathanielsz PW, Poston L \& Taylor PD 2007 In utero exposure to maternal obesity and diabetes: animal models that identify and characterize implications for future health. Clinics in Perinatology 34 515-526. (doi:10.1016/j.clp.2007.09.005)

Ogden CL, Carroll MD, Kit BK \& Flegal KM 2012 Prevalence of obesity in the United States, 2009-2010. NCHS Data Brief 2012 (82) 1-8.

Oge A, Isganaitis E, Jimenez-Chillaron J, Reamer C, Faucette R, Barry K, Przybyla R \& Patti ME 2007 In utero undernutrition reduces diabetes incidence in non-obese diabetic mice. Diabetologia 50 1099-1108. (doi:10.1007/s00125-007-0617-0)

Pavlovic D, Andersen NA, Mandrup-Poulsen T \& Eizirik DL 2000 Activation of extracellular signal-regulated kinase (ERK)1/2 contributes to cytokineinduced apoptosis in purified rat pancreatic $\beta$-cells. European Cytokine Network 11 267-274.

Petrovsky N, Silva D, Socha L, Slattery R \& Charlton B 2002 The role of Fas ligand in $\beta$ cell destruction in autoimmune diabetes of NOD mice. Annals of the New York Academy of Sciences 958 204-208. (doi:10.1111/j.1749-6632.2002.tb02970.x) 
Portha B, Chavey A \& Movassat J 2011 Early-life origins of type 2 diabetes: fetal programming of the $\beta$-cell mass. Experimental Diabetes Research 2011 105076. (doi:10.1155/2011/105076)

Poston L 2012 Maternal obesity, gestational weight gain and diet as determinants of offspring long term health. Best Practice \& Research. Clinical Endocrinology \& Metabolism 26 627-639. (doi:10.1016/j. beem.2012.03.010)

Rabinovitch A 1998 An update on cytokines in the pathogenesis of insulin-dependent diabetes mellitus. Diabetes/Metabolism Reviews 14 129-151. (doi:10.1002/(SICI)1099-0895(199806)14:2<129::AIDDMR208>3.0.CO;2-V)

Rabinovitch A \& Suarez-Pinzon WL 1998 Cytokines and their roles in pancreatic islet $\beta$-cell destruction and insulin-dependent diabetes mellitus. Biochemical Pharmacology 55 1139-1149. (doi:10.1016/ S0006-2952(97)00492-9)

Reynolds LP \& Caton JS 2012 Role of the pre- and post-natal environment in developmental programming of health and productivity. Molecular and Cellular Endocrinology 354 54-59. (doi:10.1016/j.mce.2011.11.013)

Rogers P \& Webb GP 1980 Estimation of body fat in normal and obese mice. British Journal of Nutrition 43 83-86. (doi:10.1079/BJN19800066)

Sgouroudis E \& Piccirillo CA 2009 Control of type 1 diabetes by CD4+ Foxp $3+$ regulatory $T$ cells: lessons from mouse models and implications for human disease. Diabetes/Metabolism Research and Reviews 25 208-218. (doi:10.1002/dmrr.945)

Thomas HE, Graham KL, Chee J, Thomas R, Kay TW \& Krishnamurthy B 2013 Proinflammatory cytokines contribute to development and function of regulatory T cells in type 1 diabetes. Annals of the New York Academy of Sciences 1283 81-86. (doi:10.1111/j.1749-6632.2012.06797.x)

White C, Purpera M \& Morrison C 2008 Maternal adiposity predisposes offspring to obesity independent of maternal diet. Obesity 16 S74-S74.
Wicker LS, Todd JA \& Peterson LB 1995 Genetic control of autoimmune diabetes in the NOD mouse. Annual Review of Immunology 13 179-200. (doi:10.1146/annurev.iy.13.040195.001143)

Yan X, Zhu MJ, Xu W, Tong JF, Ford SP, Nathanielsz PW \& Du M 2010 Up-regulation of Toll-like receptor 4 /nuclear factor-kappaB signaling is associated with enhanced adipogenesis and insulin resistance in fetal skeletal muscle of obese sheep at late gestation. Endocrinology 151 380-387. (doi:10.1210/en.2009-0849)

Yan X, Huang Y, Wang H, Du M, Hess BW, Ford SP, Nathanielsz PW \& Zhu MJ 2011 Maternal obesity induces sustained inflammation in both fetal and offspring large intestine of sheep. Inflammatory Bowel Diseases 17 1513-1522. (doi:10.1002/ibd.21539)

Zhang Y, Proenca R, Maffei M, Barone M, Leopold L \& Friedman JM 1994 Positional cloning of the mouse obese gene and its human homologue. Nature 372 425-432. (doi:10.1038/372425a0)

Zhang L, Long NM, Hein SM, Ma Y, Nathanielsz PW \& Ford SP 2011 Maternal obesity in ewes results in reduced fetal pancreatic $\beta$-cell numbers in late gestation and decreased circulating insulin concentration at term. Domestic Animal Endocrinology 40 30-39. (doi:10.1016/ j.domaniend.2010.08.004)

Zhu MJ, Du M, Nathanielsz PW \& Ford SP 2010 Maternal obesity up-regulates inflammatory signaling pathways and enhances cytokine expression in the mid-gestation sheep placenta. Placenta 31 387-391. (doi:10.1016/j.placenta.2010.02.002)

Received 28 November 2013

First decision 27 January 2014

Revised manuscript received 14 March 2014

Accepted 1 April 2014 